Georgia State University

ScholarWorks @ Georgia State University

\title{
Creating Support Systems for Black Women in Nontraditional STEM Career Paths
}

\author{
Tokiwa T. Smith
}

Natasha N. Johnson

Georgia State University, njohnson93@gsu.edu

Follow this and additional works at: https://scholarworks.gsu.edu/cj_facpub

Part of the Criminology and Criminal Justice Commons, and the Teacher Education and Professional Development Commons

\section{Recommended Citation}

Smith, T. T., \& Johnson, N. N. (2019). Creating Support Systems for Black Women in Nontraditional STEM Career Paths. In Thomas, U., \& Drake, J. (Ed.), Women's Influence on Inclusion, Equity, and Diversity in STEM Fields (pp. 108-142). IGI Global. https://doi.org/10.4018/978-1-5225-8870-2.ch005

This Book Chapter is brought to you for free and open access by the Department of Criminal Justice and Criminology at ScholarWorks @ Georgia State University. It has been accepted for inclusion in CJC Publications by an authorized administrator of ScholarWorks @ Georgia State University. For more information, please contact scholarworks@gsu.edu. 


\section{Women's Influence on Inclusion, Equity, and Diversity in STEM Fields}

Ursula Thomas

Georgia State University, USA

Jill Drake

University of West Georgia, USA

A volume in the Advances

in Educational Marketing,

Administration, and Leadership

(AEMAL) Book Series 
Published in the United States of America by

IGI Global

Information Science Reference (an imprint of IGI Global)

701 E. Chocolate Avenue

Hershey PA, USA 17033

Tel: 717-533-8845

Fax: 717-533-8661

E-mail: cust@igi-global.com

Web site: http://www.igi-global.com

Copyright (C 2019 by IGI Global. All rights reserved. No part of this publication may be reproduced, stored or distributed in any form or by any means, electronic or mechanical, including photocopying, without written permission from the publisher.

Product or company names used in this set are for identification purposes only. Inclusion of the names of the products or companies does not indicate a claim of ownership by IGI Global of the trademark or registered trademark.

\section{Library of Congress Cataloging-in-Publication Data}

Names: Thomas, Ursula, 1972- editor. I Drake, Jill, 1968- editor.

Title: Women's influence on inclusion, equity, and diversity in STEM fields /

Ursula Thomas and Jill Drake, editors.

Description: Hershey, PA : Information Science Reference, [2019]

Identifiers: LCCN 2018060059| ISBN 9781522588702 (hardcover) I ISBN

9781522592273 (softcover) I ISBN 9781522588719 (ebook)

Subjects: LCSH: African American women physicians. I African American women scientists.

Classification: LCC R153 .W66 2019 | DDC 610.82--dc23 LC record available at https://lccn.loc. gov/2018060059

This book is published in the IGI Global book series Advances in Educational Marketing, Administration, and Leadership (AEMAL) (ISSN: 2326-9022; eISSN: 2326-9030)

British Cataloguing in Publication Data

A Cataloguing in Publication record for this book is available from the British Library.

All work contributed to this book is new, previously-unpublished material.

The views expressed in this book are those of the authors, but not necessarily of the publisher.

For electronic access to this publication, please contact: eresources@igi-global.com. 


\title{
Chapter 5 \\ Creating Support Systems for Black Women in Nontraditional STEM Career Paths
}

\author{
Tokiwa T. Smith \\ Kemet Educational Services, USA \\ Natasha N. Johnson \\ https://orcid.org/0000-0001-8145-2153 \\ Georgia State University, USA
}

\section{ABSTRACT}

Although careers in science, technology, engineering, and mathematics (STEM) fields are widely acknowledged as central to the future, women remain largely underrepresented in these spheres. This is particularly true for Black women, highlighting the necessity of support systems and resources designed to promote their success in STEM. Ideally, these supports should begin during the K-12 years and continue throughout the course of their educational journeys. Current research indicates that Black women in STEM achieve greater, lasting success when they have access to structured support systems. As the career paths of Black women in STEM continue to evolve, there remains a need for adaptable structures and resources that are applicable to their unique needs. Yet, these supports often do not exist for those pursuing nontraditional STEM career paths. Therefore, this chapter underscores the need for Black women in STEM to establish their own support systems, aligned with their specific career paths. 


\section{INTRODUCTION}

A mere $2 \%$ of all current, practicing scientists and engineers are Black women (National Science Foundation, 2015). Despite the fact that careers in science, technology, engineering, and mathematics (STEM) fields are widely acknowledged as essential to the future, Black women remain underrepresented in most of these spaces. This severe underrepresentation can be linked to the numerous issues that Black women face early in and well throughout the STEM career pipeline. The low number of Black women in STEM college courses can be attributed in part to the limited STEM course offerings typical of the institutions in which low-income schools and students of color disproportionately attend (Carlone \& Johnson, 2007; Ong, Wright, Espinosa, \& Orfield, 2011). In addition, the presence of pervasive racial and gender stereotypes likely discourages some Black women from pursuing STEM pathways (Perry, Link, Boelter, \& Leukefeld, 2012; RiegleCrumb \& Grodsky, 2010). Similar stereotypes of this nature also underlie instructor bias, which undermines both the educational experience and the outcomes of many Black women who do pursue STEM fields and pathways (Hill, Corbett, \& St Rose, 2010). Numerous studies show the tendency of educational professionals to steer Black girls towards classes in social work and sociology, instead of encouraging them to excel in the sciences. In general, black women who are steered away from the rigor of mathematics and science courses in high school (e.g., Advanced Placement and Honors courses) later face limited collegiate and professional prospects related to these same courses of study (Willingham \& Cole, 2013).

Notwithstanding all of these imbedded structural and societal obstacles, many black girls and women do persist in K-20+ STEM courses, majors, and careers (Espinosa, 2011; Johnson, 2011; Collins et al., 2009). Existing research sheds light on the ways in which some students are able to cope with racial and gender stereotypes and other forms of bias while still maintaining high progress and achievement in the STEM fields (Cole \& Espinoza, 2008; Museus, Palmer, Davis, \& Maramba, 2011; McGee, 2014, 2015; Perna et al., 2009). There are two primary reasons for the existence and persistence of bias against black women in the STEM. First, documented studies of tokenism show that bias tends to occur more often in fields where women make up less than 15-20\% of students (i.e., burgeoning professionals). Biology aside (Kanter, 1977), this is common in the majority of STEM-based disciplines. 
Second, studying the paradox of meritocracy in organizations, Castilla and Benard (2010) found that bias is more common in fields like science and engineering, spheres which are viewed as highly meritocratic by practitioners. Their work revealed that attempts to reduce bias might actually trigger it; this is particularly the case in organizational contexts that place special emphasis on the values of meritocracy. According to Castilla and Benard (2010), this "paradox of meritocracy is of theoretical relevance because it provides an insight into why gender and racial disparities persist within job titles and work establishments, especially given the recent shift to employer procedures emphasizing merit and pay for performance" (p. 572)

We emphasize the importance of promoting the successes of black women in STEM. Connectedly, it is just as important to note the varying proclivities of their experiences while working to achieve success in the STEM fields (Chubin, 2007; Fries-Britt \& Holmes, 2012; Gasman et al., 2009). We highlight the diverse ways in which Black women interpret, respond to, and cope with racialized, gendered, and race-gendered experiences while pursuing academic degrees. Further, we identify the importance of creating support systems for those black women who are destined for careers in STEM. This includes the need for stakeholders to focus on how African American undergraduate and graduate women in STEM identify and respond to racialized and gendered forms of bias (McGee \& Bentley, 2017). Through this work, we seek to add to the growing body of literature regarding the underrepresentation of black women in STEM and the need for positive, concrete support systems - especially for those in nontraditional career paths - in the effort to promote equity, inclusion, and full representation in the STEM fields. An objective of this piece, in examining the impacts of structural racism, sexism, and discrimination, are to create implications and recommendations for improvement related to the progress, status, and success of Black women in and aspiring towards STEM-based careers.

\section{BECOMING A STEM PROFESSIONAL BEGINS WITH A STRONG K-12 EDUCATION}

Born and raised in Miami, Florida, the first author (hereafter referred to as author \#1) attended Dade County Public Schools during the 1980s and 
1990s. Her K-12 education adequately prepared her for college as well as for the selection of a STEM major. Her teachers provided her with quality STEM instruction and she engaged in a plethora of project-based learning experiences. Her classroom learning was enhanced and STEM concepts were reinforced with field trips to places such as science museums, beaches and parks. Most importantly, while in high school, she had access to rigorous STEM courses, meaning that she not only met all of the college admissions requirements, but additionally, she was confident in her level of preparation for the college environment.

Upon graduating from high school and enrolling in Florida Agricultural and Mechanical University (FAMU), author \#1 envisioned and prepared for a career as a Chemical Engineer. However, in the 17 years since graduating from FAMU, she has never held a position in that specific field. Her STEM degree, and the skills developed while obtaining it, made for a fluid transition to a Nontraditional STEM Career as a Science, Technology, Engineering and Mathematics (STEM) Educator and Social Entrepreneur. As a general rule of thumb, black women STEM professionals pursuing traditional career paths do have access to several support systems and resources, such as professional societies, affinity groups and professional development opportunities within their respective organizations. However, when seeking to pursue a nontraditional STEM career path, these same support systems are not always viable or available. For this reason, author \#1 posits that the solution lies in the creation of neoteric support systems. These systems should include resources and professional development opportunities, directly aligning with one's interests, skills, and career goals. In this chapter, author \#1 will share her strategies for creating her own supports and securing resources as she navigated her nontraditional STEM career path.

The second author (hereafter referred to as author \#2) was born and raised in Brooklyn, New York. During her K-12 years as a student in the New York City public school system, she had a particular aptitude for mathematics learning and the math environment. Scoring well every year on the yearly, summative statewide exams, one would believe that a math-related path might just be in her future. Yet, the opportunities to develop this capability were minimally existent. Despite this, she continued to excel throughout the course of her time as a student in the K-8 educational sphere. Upon entering high school, her interests changed, and she no longer envisioned the STEM field 
as an option. While there are numerous reasons for this, the lack of tangible, sustained structures and supports served as a major factor in her declining interest in mathematics. As was the case with author \#1, author \#2 was also exposed to upper-level, rigorous STEM courses, given that she attended a STEM-rooted high school. She, too, was confident both in meeting all of the admissions requirements for her chosen university as well as in her level of preparation for the collegiate environment.

Author \#2 spent her undergraduate years as a student at New York University. After being an undecided major for two years, she eventually chose a nonSTEM major. The driving forces behind this decision included the expiring 4-year time frame, the number of previous credits already accrued, and the lack of advisement specifically tailored to her and her particular needs. Just one year after graduating from college, she took advantage of the opportunity to teach under a 'teacher shortage license area' and she became provisionallylicensed middle school science teacher. Although she did not graduate with a STEM-related college degree, her background, skills, knowledge-base and overall excitement about STEM served her well. She taught MS science for two years and the next five years teaching high school Algebra, Geometry, and Trigonometry. Again, despite her non-STEM college degree, she was able to draw from the skills she developed during her years in the K-12 setting. This renewed interest and commitment to STEM remains important - although she is no longer in the traditional $\mathrm{K}-12$ classroom, since then, she has served as a math curriculum developer, interventionist, researcher, and advocate. Today, she remains adamant about the importance of visibility for black women in and aspiring towards careers in the STEM fields.

Though varying, these recollections similarly shed light on the significance of positive, early experiences women's journeys to becoming STEM professionals. The nontraditional paths and experiences of both authors 1 and 2 sustain the importance of setting a strong foundation for the continued development of women in STEM careers. Much of this preparation can be directly attributed to the quality of STEM curriculum and instruction during the K-12 years. The setting of - and basis for - this foundation begins with the first day of kindergarten and continues throughout the course of high school. Do K-12 educators feel adequately prepared to teach STEM? Do students engage in project-based learning in the classroom space and during their time in after school time programs? Is classroom learning enhanced with 
supplements such as field trips and school-based STEM events (e.g., career days and science fairs)? Is there sufficient time allocated to STEM programs, clubs, and activities outside of school? If so, are students actively participating in events of this nature? Are students granted enough opportunities to enroll in rigorous STEM courses in middle and high school? As a general rule of thumb, black women STEM professionals pursuing traditional career paths do have access to several support systems and resources, such as professional societies, affinity groups and professional development opportunities within their respective organizations. However, when seeking to pursue a nontraditional STEM career path, these same support systems are not always viable or available. For this reason, author \#1 posits that the solution lies in the creation of neoteric support systems. These systems should include resources and professional development opportunities, directly aligning with one's interests, skills, and career goals. In this chapter, author \#1 will share her strategies for creating her own supports and securing resources as she navigated her nontraditional STEM career path.

As early as the primary years, girls can and do exhibit interest, academic achievement, and unique capabilities in the sciences. Far too often, however, they are not necessarily encouraged to develop and pursue their STEM-related interests and abilities. Extant research indicates that generally, girls' interest in STEM peaks during the middle school, but begins declining by the time they reach high school. In a recent quantitative research study conducted by Microsoft, survey results found that in Europe, girls generally gain an interest in STEM at around the age of 11, but this fascination tapers off at around the age of 15 . In the related article documenting study results, the authors wrote:

Little girls dream big in this short film from Microsoft, talking about their passion for curing breast cancer, cleaning up the environment and bringing fresh water to the world. Doctors, inventors, entrepreneurs-it's easy to envision these determined, articulate and thoroughly woke kids stepping easily into any of these roles. But hold up. The statistics say otherwise. Only 6.7 percent of U.S. women and 16 percent of women globally graduate college with science, technology, engineering and math (STEM) degrees, the minimovie tells its participants. Pulling no punches, it continues: "Odds are you won't solve these problems." The youngsters' faces fall, and their resolve, it would seem, falters. Or does it? (Stanley, 2017). 
Though seemingly bleak, this story does have a happier ending. At the end of the video is the following quote: "Change the world. Stay in STEM." In essence, this quote is a charge of sorts, imploring young women to do their part to transform the current system by changing the numbers and making a mark in what has been, historically, a traditionally male-heavy realm. Additionally, the girls who were featured in the video were undeterred. According to one participant, "there's always going to be someone who says you can't do it. I think I can"; another participant unequivocally declared that she "will discover a cure for breast cancer" (Stanley, 2017).

As black women who were both skilled and interested in STEM from an early age, we can both attest to the insufficient number black women STEM professional role models for us and our peers while growing up. Author \#1 recalls the following two role models in her network: her maternal aunt, a microbiologist, and her mother's friend, a civil engineer. Despite the lack of role models, she remained interested in pursuing a STEM career. As a girl who loved math and science, she was encouraged by her teachers throughout my K-12 years to excel in these subjects. The most encouragement came from two of her STEM teachers, also black women: her sixth grade science teacher, Mrs. Richardson, and her tenth grade chemistry teacher, Mrs. Shy. As for author \#2, the landscape was drastically different. With no black women in STEM to draw inspiration from, her heroines included Dr. Mae Jemison, the NASA astronaut, Bessie Coleman, the aviator, and Katherine Johnson, the mathematician. The lack of tangible role models in her life was a primary factor in author \#2's diminished interest in STEM during her time in high school as well as in college.

The combination of inhospitable societal factors coupled with a lack of direct access both serve as contributory culprits in this regard (Barone, 2017). In addition, the low number of women in STEM-based careers means that girls do not always have physical role models to aspire towards. As this is the case for women in general, this reality is even more pronounced for girls and women of color. For example, author \#1 noted:

One of the things in my childhood that would have better prepared me for college is participation in out of school time STEM programs. Other than working on projects for science fairs, I did not participate in any out of school time STEM activities, clubs or programs. 
This evidences the need for formal-as well as informal- learning opportunities, designed with a focus on creating access, and building confidence in females as they express interest in and pursue STEM-related careers (Weber, 2011). Increased participation in out of school programs can potentially create, build, and increase students' confidence in STEM. Out of school time supplements classroom learning by providing students with additional opportunities to engage in hands-on STEM and academic development activities. These programs also create environments in which students can form bonds with other, likeminded peers as well as with mentors who can potentially serve as their role models.

\section{THE ROLE OF ACADEME IN PREPARING BLACK WOMEN FOR STEM CAREERS}

\section{Author \#1: The Role of HBCUs in Preparing Black Women for STEM Careers}

In 1996, I graduated from high school and enrolled in FAMU as a chemical engineer major. Although I did not know it at the time, attending FAMU was a great choice for me and critical to the successful attainment of my Bachelors of Science in Chemical Engineering. According to a National Science Foundation (NSF) study conducted in 2004, between 1997 and 2001, eight of the nine colleges and universities that awarded the highest number of Bachelors of Science degrees in STEM to African Americans were HBCUs (NSF, 2015). Those nine institutions included my alma mater FAMU, Hampton University, Howard University, Morgan State University, North Carolina Agricultural and Technical University, Southern University A \& M College at Baton Rouge, Spelman College, University of Maryland at College Park and Xavier University of Louisiana.

In 2001, the year in which I graduated from FAMU, black women received $36 \%$ of the bachelor's degrees awarded in engineering. According to data from the Integrated Postsecondary Education Data System (IPEDS), in 2004, $22 \%$ of all bachelor's degrees were awarded to African Americans, but only $30 \%$ of all bachelor's degrees awarded to African Americans were in STEM. 
IPEDS data revealed that in 2004 that $33 \%$ of the bachelor's degrees awarded to black women in STEM were from HBCUs, compared to $26 \%$ of the degrees awarded to black men in STEM (NSF, 2015).

Florida A \& M University shaped my career tremendously; I would not be where I am personally or professionally without FAMU. It was a supportive environment where the faculty and staff provided great educational experiences, preparing me well for post-graduation opportunities. At FAMU, many of the faculty conducted study sessions and were available during office hours. There were free on-campus, tutorial programs, study groups with classmates and peer mentors. Upperclassmen and alumni supported the underclassmen's academic, professional and emotional development.

FAMU's infrastructure supports its students' career and professional development. The career center hosts career and graduate school fairs each semester in which corporations, government agencies and universities recruit students for summer research positions, internships, jobs and graduate school opportunities. The career center schedules interviews with students for organizations that come on campus to hire students for job, co-op and internships. The career fair also host workshops that teach students how to write resumes, cover letters and develop soft skills that are important for career success. There are also research training programs that provide opportunities for students to conduct research on and off campus. FAMU's campus also had student chapters of STEM professional societies for STEM majors such as American Institute of Chemical Engineers (AIChE), National Society of Black Engineers (NSBE) National Organization for the Professional Advancement of Black Chemists and Chemical Engineers (NOBCChE) and Society of Women Engineers (SWE).

While in college, I utilized all the resources that were accessible to me for my career development. The College of Engineering was assigned a career counselor who provided guidance in the development of my resume and soft skills. She coached me on interview skills which assisted me in securing a summer internship with SC Johnson. The last three years of my college career during the academic year, I conducted biomedical research with a chemistry professor. My research experience enhanced my classroom learning experience providing an opportunity for me to learn additional laboratory skills and research techniques. I refined my oral and written communication skills by 
presenting my research at scientific meetings. At these meetings, I expanded my network and acquired new knowledge at the professional workshops and other conference events.

\section{Author \#2: The Role of PWls in Preparing Black Women for STEM Careers}

I was thrilled at the opportunity to become a member of New York University. Presently, NYU receives over 80,000 applications from prospective students yearly. It goes without saying that I understood the prestige and status that came with joining the NYU community in 1996. As an incoming freshman, I was accepted into the university's C-STEP (College Science, Technology, and Engineering) program for 'underserved students'. The goal of this program was to offer us intensive support, advisement, and direction, keeping us on-track throughout the course of our time at the university. As with any program, the title is only as good as the people behind it. That is to say, while on paper, this was promising, the truth was, not many people at the time were equipped with the knowledge and tools necessary to teach to the rudiments of science, technology, and engineering. I remember, as an undergraduate, regularly celebrating that considering the numbers - black students make up roughly $10 \%$ of the school's total population of over 60,000 - we celebrated the fact that while so many others did not make it, we were there.

I graduated from high school with both a HS diploma and a regents' diploma, signifying that I had passed all of the necessary exams to achieve this separate distinction. As was previously mentioned, I always did well enough in math; my math scores and results remained strong throughout my time in high school. This is significant because during my freshman year, my advisor enrolled me into an honors math course. All of my peers took the 'regular' course, and at the end of the semester, most of them received "A's", while I had the 'honor' of earning an advanced ' $C$ '. Adding insult to injury, my transcript never reflected the fact that I had taken an honors course, so that ' $\mathrm{C}$ ' meant little to both me and to my GPA. After that experience, I decided I would not bother to take more 'advanced' or 'rigorous' courses if I would not receive any credit for it. Before the start of my junior year, I ended up transferring from the College of Arts and Sciences to the Steinhardt School of Culture, Education, and Human Development. Upon graduating 
from NYU in 2000 with a Bachelor of Science in Communication Studies, I felt prepared and ready to take on the world.

In 2001, after a year of temporary work, internships, and 'finding myself', I received a phone call from a friend, alerting me to the teacher shortage in NYC at the time. The shortage areas then are the same as they are now: math, science, foreign language, and special education. I remember completing the necessary paperwork, being fingerprinted, and preparing myself for the interview process. Three day later, I was assigned to my first, professional teaching position - as a $6^{\text {th }}$ grade science teacher, with a primarily special education student population - in the South Bronx. Even though it was not my assignment of first-choice, because of my background and preparation (Brooklyn Technical High School + New York University), I was and remained ahead of the curve.

Education, in general, is a sphere in which upwards to half of all teachers do not make it to the end of the fifth year. This reality is further compounded by the many still existing vacancies in certain shortage area fields (i.e., math, science, foreign language, and special education, to name a few). What I did not realize then was that I was being afforded a second opportunity to correct the things I believed needed to be attended to. My experiences in both HS - an environment in which black students were roughly $33 \%$ of the total population, and during my undergraduate years - an environment in which African Americans are approximately $10 \%$ of the student population - were fundamental to my preparation for and decision to confidently accept the position of K-12 STEM educator within the NYC Department of Education.

\section{UNDERTAKING THE NON-TRADITIONAL STEM CAREER PATH}

\section{Author \#1}

I graduated from FAMU in 2001 confident and well prepared to start my career as a chemical engineer. I entered the workforce equipped with my degree, great professional skills and an amazing network of peers and mentors. My network included amazing Black Women in STEM; many were fellow HBCU alumnae. It wasn't my plan to pursue a non-traditional career path, 
I left FAMU wanting to pursue a career in chemical engineering. However, a job offer that I received in this field was rescinded due to an economic downtown. A few months after graduation, my non-traditional career path began, after a friend of a mentor hired me to work for their Bridges to the Baccalaureate Program. This program, at Georgia State University, supported community college STEM majors in their transition to a 4 year institution to complete their bachelor's degrees.

When I accepted this position in 2002, I thought it was a temporary path. However, that first non-traditional STEM position was the start of a 17 year career working in academia, government and philanthropy. Actually, that role opened the door to other positions that facilitated my transition from a Chemical Engineer to a STEM Educator. For about 2 years, I coordinated out of school time and tutorial programs at elementary and middle schools. For 6 years, from 2004-2010, I held two positions at Spelman College developing and managing academic support, pre-college science outreach and undergraduate research training programs. For 3 years, I developed and implemented STEM curriculum for out of school time programs for elementary and middle school students. For one year, I went back to academia and coordinated professional development programs for undergraduate STEM majors at California State University at East Bay. My most recent position was serving as the K-16 Education Program Manager for Lawrence Berkeley National Laboratory.

I embarked on the part of my career as Social Entrepreneur in 2005, when I established my nonprofit organization Science, Engineering and Mathematics Link also known as SEM Link. A few years into my career in STEM Education, I observed many things in the STEM Educational experiences for K-12 students that I wanted to change. Therefore, I decided to utilize my background as a chemical engineer to create an organization that would implement the improvement in the way youth are expose to and prepared for pursuing STEM careers.

The premise of SEM Link's work is the belief that exposure to the STEM community is critical to K-12 student achievement and career exploration in STEM. The organization's mission is to promote student achievement and career exploration in STEM while increasing student exposure to the STEM communities. SEM Link's two core program model, Experimental Design Program and Math and Science Career Academy, connects the STEM community to youth to provide opportunities for them to engage in hands-on 
STEM activities, explore STEM careers and learn about real-world applications of STEM in their classrooms, out of school time programs and communities.

In 2010, I launched my STEM Educational Consulting Firm, Kemet Educational Services (Kemet Education). Kemet Education focuses on ensuring the pre-college, community college and undergraduate students are prepared to pursue STEM Careers. This consulting firm allows provide an outlet for me to explore other interests and do work in STEM Education that are outside the scope of work of my nonprofit.

\section{Author \# 2}

It did not take long for me to realize, during the first years of my educator journey, that most K-12 educators are not scientists or mathematicians. I often use the term, "sink or swim" to describe my initial teaching experience. I entered the realm with no mentorship of any kind, limited resources, and not to mention, my first assignment was in the South Bronx. This matter was further compounded by the fact that although I had no special educational licensure, I was given the task of teaching a population labeled "special ed." To call this a non-traditional path is an understatement, to say the least. Throughout the duration of that time, as I worked through the murk, the more experienced teachers in the teachers' lounge only had one piece of advice for me: "come back tomorrow". That was it. Success, at that time, was defined solely by my ability to 'take it', go home to reset, and return again tomorrow. While I would not consider that a strategy, it worked. I did what I knew how to do, which was sift through my very limited resources, create and execute daily plans, work on my own classroom management capabilities, and no matter how hard any given day was, I knew I had to make the daily commitment to 'come back tomorrow'.

According to Bentley (2017), "intrinsic inequities in STEM have been highlighted by scholars for decades and empirical studies have illustrated how the competitive culture of post-secondary STEM departments may constitute an unsupportive space for some underrepresented minority (URM) students" (p. 2). Moreover, numerous research studies conducted by Seymour and Hewitt (1997) and Hurtado, Eagan, Tran, Newman, Chang, \& Velasco (2011) indicate that in addition to this, the presence of structural and institutional barriers at the post-secondary level also serve as potential 
barriers to and for underrepresented students. Examples of this include STEM faculty who, subliminally or overtly, do not equally support all their students, a lack of adequate recruitment of underrepresented minorities into undergraduate research programs, and a paucity of sufficient minority role models and support for Black STEM undergraduates (e.g., Borum \& Walker, 2012; Seymour \& Hewitt, 1997). Further, a synthesis of 40 years of research on the college STEM experiences of women of color (Ong, Wright, Espinosa, \& Orfield, 2011) revealed several factors that directly impacted their retention, experiences, and achievement in STEM programs, including "the overall climate in STEM learning environments" (p. 177).

An analysis of interview and journal data, conducted by Flaherty (2018), revealed that many women who enter STEM are immediately made "cognizant of their race and gender identities, naming them in isolation and intersectionally as a potential risk or as being protective, positive, and empowering for their STEM engagement" (pg. 1). Time and time again, much of the existing research regarding women and women of color in STEM focuses on the numerous hurdles women face in longstanding, traditionally-based spaces. In sum, these author-based revelations, coupled with the growing research in this realm underscore the growing need for spaces, cultures, and experiences that are conducive to the productive growth and development of all who are underrepresented in these capacities (Bentley, 2017; Espinosa 2011; McGee \& Bentley, 2017).

\section{DISCOVERING TRADITIONAL PROFESSIONAL SUPPORT SYSTEMS NO LONGER SERVED ME}

\section{Author \#1}

Even though I attended traditional STEM conferences, I was no longer making contributions to these conferences or using the information gathered to continue developing my career. I was not presenting research, nor was I recruiting for my own organization. The research talks and the poster sessions no longer captivated my attention because I was not studying or working directly in those fields. This was compounded by the fact that the professional development sessions I attended were not relevant to me, my career path, or my career development. For years, I kept attending these conferences in 
order to support my friends, and when I was the coordinator of the Howard Hughes Program at Spelman College, to support the students involved in my research programs. I eventually stopped attending these conferences mainly because I no longer believed it was a right fit for me. As for the traditional space, I found that it was designed for individuals who were already in or aspiring towards traditional STEM career paths.

While still working at Spelman, I began attending conferences for STEM Educators and higher education professionals. One of the main conferences that I attended was the National Science Teachers Association (NSTA). Initially, these conferences were beneficial for my professional development. I acquired new knowledge and expanded my network; this proved to be very beneficial to my career as I transitioned from a Chemical Engineer to a full-blown STEM Educator. I learned about educational pedagogy and best practices for developing and implementing STEM curriculum. However, after a few years, similar to my experiences with customary STEM conferences, I became uninterested in the research talks and the professional development sessions. I was neither a classroom teacher nor a faculty member; I considered myself to be a STEM professional, thusly, I experienced a sense of isolation in these spaces. For this reason, I did not make very many connections. Ultimately, I stopped attending these STEM education conferences because, simply put, this was not a place in which I felt I could belong or receive the support I needed.

With the formation of my social enterprises, I wanted to acquire new knowledge and expand my network in the entrepreneurship and philanthropy spaces. Yet, I felt uncomfortable in the philanthropic realm because there are very few black women in that space. In STEM as well as in STEM education, there are several organizations that provide inclusive spaces for black women. I can literally count on one hand the number of organizations specifically designed to support black men and women in philanthropy. Two organizations that I am particularly familiar with are Blacks in Philanthropy and the Association for Black Foundation Executives (ABFE). In the same regard, there are few organizations that support black women in the entrepreneurial space; Black Women Entrepreneurs serves as an example of this. At the time in which I was still searching, there were not many social entrepreneurs or STEM educators in the entrepreneurial space. In general, I found that I was unable to have meaningful conversations or connect with many people because my businesses and work were so different from that 
of other people in these spaces. Although I easily acquired the knowledge I needed and desired from specific workshops and conferences, I continued to lack opportunities to engage in meaningful conversations and build a sizeable network of professional relationships.

\section{Author \#2}

I began attending institutional, STEM-based conferences in 2003. At the time, I was employed at a 7-12 charter school in the Lower East Side of Manhattan. Every year, the school principal sent all of the English teachers to the annual NCTE (National Council of Teachers of English) meeting, while all of math teachers were simultaneously sent to the annual NCTM (National Council of Teachers of Math) conference. I soon learned that my presence at meetings of this nature were more important than even I had originally imagined. It was not shocking to me to see very few of "us" in the math space in general; evidently, I found far fewer of "us" teaching math at the high school level. While I enjoyed partaking in these yearly conferences, it saddened me to no end to see so few of us represented, professionally, in this regard.

There were many occurrences - too many to count - in which people visibly expressed surprise at the fact that I was a STEM teacher at all. They were even more shocked when they learned that I was a high school teacher. The national NCTM convention, for example, was a space in which I gleaned extensively. I took advantage of the many resources that were available, and I could not wait to take these materials back to my classroom. Yet, this did not come without questions regarding me and my credentials, inquiries regarding what I planned to do with my accrued resources, who I planned to share them with, and who granted me access in the first place. Thankfully, instances such as this did not occur often enough to sway me in any way. Instead, it gave me an insider's perspective into the truth about what I was dealing with: unless I planned on constantly answering questions regarding the validity of my presence in the STEM sphere, unless I expected somebody else to step in an pick up the slack, I was going to have to step up and create those things/services/spaces I did not see.

I discovered that not only were traditional professional support systems not serving me, I also quickly learned that if I believed something was lacking, I could not wait for a magic formula to drop out of the sky. Rather, I saw that my visibility in the STEM sphere was - and remains - a necessity. This is 
consistent with the work of Weber (2011) who, through her work connecting positive experiences and role models on the impact of female interest in STEM, identified the following:

Formal, as well as informal, learning opportunities must be designed with a focus to create access as well as build confidence in females to pursue their interests in STEM careers (Battey, Kafai, Nixon, \& Kao, 2007; Clewell \& Campbell, 2002). Simpkins, Davis-Kean, and Eccles (2006) suggested that out-of-school math and science learning experiences in students' education, whether leisure or academic, impact their later course choices if they engage in such activities early. As students grow older, their course selections in math and science change; therefore, early out-of-school activities can influence adolescent beliefs about what they do, which can be a predictor of which math and science courses students will take at the high school level (Eccles et al., 1985; Simpkins et al., 2006). (as cited in Weber, 2011)

Described by Weber (2011) in the above-listed article, providing female students with informal STEM-related learning opportunities is an important step in expanding their interests in and knowledge about STEM areas and fields. Borum and Walker (2012) conducted a qualitative study of twelve black women in STEM in which they found that mentorship, a supportive program, and study groups were are all significant indicators that participants attributed to their success. Directly connected to the experiences of authors 1 and 2, this also includes the need to identify those spaces that are not supportive. Additional implications, suggest the authors, include "finding ways to minimize feelings of isolation... and allowing further opportunities for mentorship" (Borum \& Walker, 2012, p. 1), all for the purpose of imparting and impacting positive, institutional change.

\section{BICULTURALISM, INTERSECTIONALITY AND SYSTEMIC CHALLENGES}

Black women have to maneuver between the larger American Society and the smaller Black Community. The navigation between these two cultures means they may not feel that they belong in either setting. (Watt, 2003). Black women may be expected to behave one way at school or work and 
another at home or in their community, sometimes forming a bicultural life and becoming a marginal person. A marginal person lives on the boundary of two distinct cultures, one more powerful than the other, who does not have the ancestry or belief systems to become a full member of the dominant group (Yates, 2017). Black people everywhere take note and manage themselves in a largely white-dominated society, learning and sharing the peculiar rules of a white-dominated society. (Anderson, 2018). An example of one of these rules is "you have to work twice as hard to get half as far."

Black Women in STEM face unique challenges in the pursuit of their career paths. This often begins with varying early childhood experiences, and many of these challenges continue throughout their careers, in their current roles, and throughout the journey to their chosen career paths. Black women's experiences are shaped by their conjoined identities as both black people (Critical Race Theory) and as women (Feminist Theory). This duality, often referred to as intersectionality, creates a multiplicity of experiences not commonly shared among other women in general (Crenshaw, 1990). This includes this connection (or lack thereof) to other women of color. This duality, the intersection of race and sex, is associated with longstanding racial and sexist prejudices in the United States of America. Existing research, evaluating the unique effects of race and gender, tend to treat these constructs as separate and distinct variables. Implied in this separate distinction is the connotation that racial and gender components of identity can be compartmentalized and can operate independently of each other. There remains a gap in current research examining the intersectionality of race and gender, particularly as they are relevant to STEM access, persistence, and success (McCall, 2008). Race and gender have a confluent effect on the information social systems that exist and impact career advancement (Crenshaw, 1990; Yates, 2017).

Black Women in STEM experience systematic challenges that impact their ability to enter and remain in STEM careers. A primary, systematic challenge continues to lie in the perceived stereotypes and images regarding the notions of who are and are not, who can and who cannot be a STEM professional. These images and stereotypes tend to be created by the majority and by those in positions of power. The reasons for this are rooted in the desires to keep maintain the status quo, to keep others out of established positions, and to justify the lower levels statuses presently occupied by many minority groups (Rice, 2016). The stereotypical, longstanding image of a "true" STEM professional is that of a white male. Other systematic challenges include, but 
are not limited to, (1) lack of visible role models, (2) feelings of isolation, (3) stereotype threat, (4) tokenism, and (5) pay inequities (Falcioni, 2012; Flaherty, 2018; Stanley, 2017). A large number of these challenges occur at the intersection of gender, racial, and general inequality. Black women in and aspiring towards careers in STEM fields must make it their priority to stay at the forefront of this issue in the continued work to overcome these and other challenges of this nature.

\section{SUPPORT SYSTEMS FOR BLACK WOMEN IN STEM}

The support systems for Black Women in STEM, as well as for people in general, are often established during one's childhood years and then continue throughout adulthood. Russian-American Urie Bronfenbrenner was a developmental psychologist who developed the bioecological model for human growth and development. Bronfenbrenner's model is a theory of educational psychology that studies human development over time. Included in this model is Bronfenbrenner's Ecological Systems Theory, which explains how everything in a child's life and environment affects the way in which this child will grow and develop. Conceptualizing this theory, Bronfenbrenner introduced four ecological systems that an individual interacts with, each nested within the others. Listed from closest to the person to furthest, these levels are the Microsystem, Mesosystem, Exosystem and Macrosystem. The full model suggests that in sum, the interactions between individuals and their environment, categorized into various systems, shape their growth and development over time (Bronfenbrenner, 1977; Rosa, \& Tudge, 2013). .

The Microsystem is the small immediate environment the child lives in. Children's microsystems includes family, caregivers and school. The more encouraging and nurturing these relationships and places are, the better the child will be able to grow. The Mesosystem level includes is the different parts of a child's microsystem work together for the sake of the child. The Exosystem level includes the other people and places that the child herself may not interact with often the child but that still have a large effect on them, such as parents' workplaces, extended family members, and the neighborhood, to name a few. The Macrosystem, which is the largest and most remote set of people and things to a child but which still has a great influence over the child (Bronfenbrenner, 1977; Rosa, \& Tudge, 2013). 
The two levels of Bronfenbrenner's Ecological systems that apply the most of the support systems that are necessary for Black Women to persist in STEM are the Microsystem and Macrosystem. The Microsystems are support and resources on an individual and personal level. These systems include positive self-image, internal beliefs, work ethic. The Macrosystem is their external environment which includes family, schools, work. For Black women, family support and the support of teachers and mentors at work, provide confirmation and confidence that they are capable of succeeding (Bronfenbrenner, 1977; Rice, 2016).

In order to overcome the systematic opposition that Black Women in STEM experience during their career advancement they must have aspirational, navigational, social, familial and resistant capital. Aspirational capital refers to a black woman's ability maintain hope and dreams despite obstacles and barriers. Navigational capital speaks to a black woman's ability to maneuver through social institutions, arguably because of their standpoint. Being a black woman, they possess the insight of how others view them. Social capital refers to the use of the vast array of resources or networks that can be used for gaining access to various opportunities. Familial capital describes the ways in which black women carry a sense of community history, memory, and cultural intuition with them. Resistant capital refers knowledge acquired through oppositional behavior that challenges inequality (Bronfenbrenner, 1977; Yates, 2017).

Black Women in STEM gain their aspirational, navigational, social, familial and resistant capital through their relationships, organizational affiliations and education and professional development; which are the foundation for their support systems and resources for their career advancement. Relationships that Black Women in STEM develop with their colleagues and peers, supervisors and teachers, mentors and sponsors have a huge impact in her career trajectory. Relationships provide counsel, emotional support as well as individuals that will inform them of opportunities and open doors that will advance in their career. Organizational affiliations such as college and university alumni associations, fraternities/sororities, community organizations and professional societies provide opportunities for them to build new relationships, develop their soft skills and new professional expertise.

Professional Development is an essential resource for career advancement. As one's career evolves and grows, professional development is important to 
staying current in their field and be prepared for career opportunities. For Black Women in STEM, professional development opportunities usually happen within the organization that their work for and the cost for these trainings are usually covered by their organization. Other professional development opportunities for Black Women in STEM occur by attending meetings of the STEM professional societies that are specifically for women and people of color such as Women in Government, Society of Women Engineers, National Society of Black Engineers and those connected to their career field such as American Chemical Society, and the American Geophysical Union, to name a few.

\section{CREATING OUR OWN SUPPORT SYSTEMS}

\section{Author \#1}

I spent over 10 years trying to find a space where I belonged and infrastructure that supported my unique non-traditional STEM career path. I realized that space and infrastructure didn't exist and I desired to attend professional events and have a support system. Therefore, I knew that I had to create my own systems for support as a Black woman in a non-traditional STEM Career path. The support system I created contains the best parts of the combination of sectors in my career path; STEM, STEM Education, Entrepreneurship and Philanthropy.

My first step in creating my support system was determining the most important things that I needed for my career advancement. I decided that one of those things was relationships; therefore I determined the best ways to build and maintain relationships with other Black women in the sectors that made up my nontraditional career path. Black women, no matter their chosen career path, have similar experiences in the workforce. The things that I have in common with my fellow Black Women in STEM in traditional STEM paths is because there are very few Black Women in those fields. Similar to my fellow STEM Educators, there are very few Black Women in leadership nationwide in these spheres. Just like my fellow Black Women Entrepreneurs, there are challenges that we face as Black women entrepreneurs that men and women of other races don't face. As a social entrepreneur, I also needed to 
include Black women in philanthropy in my network because that is the space that I am in as a Founder and Executive Director of a nonprofit organization.

I have learned that my support system will look different than Black women in other fields. The first group in my support system is my fellow Black Women in STEM, which I affectionately call my STEMsistas. As I advance in my career, I notice the presence of more of us in non-traditional STEM career paths. The next group in my support system would be my fellow Black Women STEM educators that work in informal, formal and higher education settings. These ladies share my passion to help inspire and train the next generation of STEM professionals; especially Black girls and young women. The next group in my support system would be my fellow Black Women entrepreneurs, affectionately referred to by me as my Sistapreneurs. These ladies share my passion for entrepreneurship and desire to build wealth from our professional expertise. The final group in my support system would be my fellow Black Women in Philanthropy; these women share my desire to make an impact in my community and in the world. This tribe of Black women with a diversity of backgrounds that I have picked up along various parts of my journey ensures that I have my support system as a Black Women in a non-traditional STEM career path.

My fellow Black Women in STEM or my STEMsistas make up the majority of my tribe of Black women in the support system that I designed for myself. As a chemical engineer, even though I have chosen a nontraditional career path, I still consider myself a STEM professional. Therefore my STEMsistas are the group that I feel most connected to professionally. My STEMsistas include some of my longest friendships with Black women who I have known since my FAMU Days. These woman also include some of my protégés/little sisters that I met during the six years in which I worked at Spelman, many of whom are now STEM professionals themselves.

The main support that my STEMsistas provide is a safe space to authentically be a Black Women in STEM and all that encompasses. These are the women with whom I share and engage in conversations about various STEM topics. These women volunteer, make personal financial contributions and, when they are able, obtain resources from their organizations to support the work of my nonprofit organization. These are the women that I bounce my ideas for curriculums, programs and services for my businesses. These are also the women that I call to swap "Black Women in White Spaces" stories. These 
women understand and live in environments where they are either the only or one of a few Black women in professional environments.

The next group in my support system would be my fellow Black Women STEM Educators. These amazing ladies, I met once I transitioned into my career as a STEM Educator. I started building these relationships when I began working in higher education and with schools and school districts in a variety of roles. This group encompasses women leaders in the K-12 Education space as classroom teachers, STEM Coordinators, STEM Coaches and STEM District Leaders that are innovators and leaders in their schools and school districts. This group encompasses women leaders in higher education and informal education spaces that are STEM Program Directors and Managers, STEM Education Experts and STEM Coaches. My relationships with these women provide a space for me to merge who I am professionally as a Chemical Engineer and STEM Educator. The combination of who I am as an engineer and educator is what I draw from as inspiration when I develop my own curricula and programs. These women provide the space for me within their organization to implement my curriculum and programs. Additionally, they guide me in developing strategies for building and maintain positive relationships with educators and navigating the politics in the education space.

The next group in my support system would be my fellow Black Women Entrepreneurs, women whom I consider to be my Sistapreneurs. These women help me stay true to my goal of building wealth through social entrepreneurship. Most of these women do not have traditional STEM backgrounds or social enterprises, but we support each other in all of our entrepreneurial goals. These are the women that I have conversations with about brand development, revenue generation, social media and web presence. These are the women that check in with me and ask; "Have you reached your quarter business goals, sis?" These are the women who, when I say, "maybe I should stop this entrepreneurial journey and get a job", encourage me to keep going. They even tend to repeat to me one of my mantras: work the plan and watch the plan work. My Sistapreneurs and I celebrate each other successes and support and promote each other's businesses.

The final group in the support system that I created is Black Women in Philanthropy. None of these women have a traditional background in STEM. These are the women who remind me of the importance of my work. These women help me navigate my role as Founder and Executive Director of 
a nonprofit organization. These women ensure that I get the professional development, attend the right events and am in the right tables that will help me achieve my goals to build a sustainable nonprofit that will last beyond my lifetime.

\section{Author \#2}

Why are support systems such as these SO important? The significance of this relationship is largely to students' earliest experiences in the classroom environment. Nix and Perez-Felkner (2019), for example, saw an absence of literature examining the potential effects of difficulty perceptions on students' participation in STEM, related to their gender and race/ethnicity. Retrieving information from a nationally representative (U.S.) longitudinal data source, they measured gender and racial/ethnic variation in secondary students' orientation towards difficulty. Their purpose, in doing so, was to investigate the connection between students' beliefs in their STEM abilities and their eventual decision to earn - or not earn - STEM degrees. Looking specifically at students' difficulty perceptions and their decisions (or not) to attain physics, engineering, mathematics, and computer science (PEMC) degrees, Nix and Perez-Felkner (2019):

...observed nuanced relationships between STEM difficulty orientation, gender, racelethnicity, and PEMC major and degree outcomes. In secondary school, the gap between boys' and girls' mathematics difficulty orientations were wider than gaps between White and non-White students. Mathematics difficulty orientation was positively associated with both declaring majors and earning degrees in PEMC. This relationship varied more strongly based on gender than racelethnicity. Notably, black women show higher gains in predicted probability to declare a mathematics-intensive major as compared to all other women, given their mathematics difficulty orientations. This study's findings show that both gender and racial/ethnic identities may influence the relationship between mathematics difficulty orientation and postsecondary STEM outcomes. (p. 43)

The work of Nix and Perez-Felkner (2019) is telling because "black students were more likely to declare PEMC majors and earn these degrees than...all other students. Notwithstanding, Black men and women showed 
higher than expected gains in probability to declare a PEMC major compared to their...counterparts" (p. 59). Despite this promising information, black students, especially Black women, are generally underrepresented in all STEM fields. This suggests that factors beyond those measured by the authors (i.e., structural, systemic, institutional racism), regularly act as barriers to these students' participation in STEM-related disciplines (Falcioni, 2012; McGee \& Bentley, 2017).

It remains our determination that support systems close existing gaps between gender, race/ethnicity, and difficulty orientations in changing the trajectories of those who would otherwise shy away from the selection or attainment of a PEMC major and degree. Robinson, McGee, Bentley, Houston, \& Botchway (2016) concur with this, as they recently conducted a study with the intention of addressing negative racial and gendered experiences that discourage academic careers in STEM. In this study, Robinson et al. (2016) found a growing number of black STEM faculty members who were dissuaded from academia. Moreover, the racial and gendered experiences of study participants were principal factors impacting their choices and desires to pursue the academic route.

The presence of support systems holds much promise, given the role that educators and institutions play in encouraging underrepresented groups to select and complete STEM degrees. Nix and Perez-Felkner (2019) contend that though gender and race/ethnicity group alone does show that the magnitude of the relationship between mathematics difficulty orientation and PEMC participation varies by identity group. Programmatic innovation is needed within graduate mentoring programs to address racial, gender, and other identity-based biases within engineering and academia, in addition to traditional content that focuses on presentation skills, networking, and other professional development areas. A new approach develops a mentoring curriculum that raises racial and gender consciousness by utilizing the expertise of scholars from various social science disciplines.

\section{BLACK WOMEN IN STEM CREATING THEIR OWN SUPPORT SYSTEMS}

The journey of black women in STEM is unique, to say the least. There are a myriad of proclivities and experiences specific to the path, plight of black 
women in particular. There are naturally, things on her journey that men and women of other races, including other women of color, don't always experience. This journey starts when girls matriculate through their K-12 and post-secondary education. Are Black girls encouraged to pursue STEM? Do Black girls have Black Women in STEM as role models? Do Black girls participate in out of school time programs? If Black girls express an interest in STEM at an early age, is that interest discouraged or encouraged?

The college or university a black woman decides to attend is important to both her educational attainment as well as to her post-graduation opportunities. Research shows that Historically Black Colleges and Universities (HBCUs) continue to substantially serve the needs of black women pursuing STEM careers. It prepares them well during their undergraduate, graduate, and postgraduate years. It also allows them to take advantage of on-site mentorship and collaboration opportunities, and affords them the opportunity to build their own professional networks. This includes the development of and partnership with other, likeminded black women in STEM (i.e., peers, colleagues, mentors, and protégés).

For black women in STEM to achieve career success, they must be afforded access to spaces in which they can be free to be their authentic selves. Imbedded in this is the need for black women to connect, discuss their personal and professional experiences, and work together to develop strategies for career development. It is important for every black woman STEM professional to be intentional about creating an environment that will allow her to thrive and achieve her goals. Similarly, it is just as essential for black women who see our lack of representation to be deliberate in working to create these spaces. Far too often, women seeking to pursue non-traditional STEM career paths must create their own unique support systems. This is telling because it must happen sooner than later; for many, the making of this decision occurs much earlier in our careers than those who have chosen traditional paths. The creation of additional support systems, must be expanded to include more black women, irrespective of whether or not they have traditional STEM titles and/or traditional STEM degrees. The diversity of varied, included alternative career paths and experiences will provide Black women in STEM with the necessary resources and supports to accomplish our professional goals. 


\section{Building a Tribe of Professional Black Women}

Now that I have explained who is a part the support system I created for myself as a black woman in a nontraditional STEM career path; I will share my process for building my tribe of women. I looked for similitudes between myself and the women in my network and chose women:

- I share genuine connections with and I like talking to and spending time with them.

- I have developed meaningful and mutually beneficial relationships

- I have similar professional goals and ambition

- I deem open and flexible with their communication methods

- I share a balance of differences and similarities in our personalities, backgrounds and perspectives

- I believe value honesty and transparency.

The process for determining what women constitute my tribe of Professional Black Women took a lot of self-reflection. It started with discovering who I wanted to be and what I wanted to accomplish as a STEM Educator and Social Entrepreneur. Next, I wrote down my short term, midterm and long term goals. Then, I identified my strengths that would advance the achievement of those goals. The process of identifying my strengths guided my discovery process of the areas that required support from others. The initial women that became a part of my tribe women that were already a part or connect to my personal and/or professional networks. Over the years, I've added members to my tribe via social media at professional and social events.

\section{The Role of Social Media in Building a Tribe}

Social media is a critical part in building one's professional brand and expanding one's network. It is important to create a professional presence on social media which starts with a LinkedIn account and possibly Instagram and Twitter accounts. Building a professional social media presence starts with a professional photo and a brief bio. On platforms such as LinkedIn, share users professional experience, publications and volunteer experiences. 
Professional social media should include post about one's work and industry, articles about topics in their industry and posts shared from one's connections.

Social media is a great way to expand one's network and find individuals to add to their support system. Individuals stay connected and build relationships online by sharing, liking and commenting on each other post. Individuals can engage in dialogue via direct message. The highest level engagement with folks in your network on social media is to schedule a time to talk on the phone or via videoconference or when in the same city meeting up in person.

\section{MAKING PROGRESS: IMPLICATIONS FOR CHANGE}

Progress in K-12 STEM integration needs to come on multiple fronts. Among these are curricula development, teacher and administrator education initiatives, school change initiatives, and policy initiatives. The following, according to Moore and Smith (2014), highlight some key implications for change relevant to the following four areas:

- There is a need for curricula that integrate STEM contexts for teaching disciplinary content in meaningful ways that go beyond the blending of traditional types of understandings. Curricula that integrate STEM are rare for K-12 spaces, and of those that do, even fewer are researchbased and have meaningful mathematics and science. Funding to back new research-based STEM integration curricular innovations is needed and should be targeted. (p. 7)

- Teachers and administrators need professional learning experiences that prepare them to work within and develop STEM integration learning environments for K-12 students. Most instructors, teachers, and administrators have not learned disciplinary content using STEM contexts, nor have they taught in this manner, and therefore new models of teaching must be developed if STEM integration is to lead to meaningful STEM learning. Programs should be developed at local and state levels to promote this change in practice. School change is needed to support STEM integration. Schools are set up to silo the 
disciplines of STEM. This separation is an artifact of history. While it is good to learn each subject as a stand-alone, it is also imperative that students see the interconnectedness of the subjects they are learning. (p. 7)

- Schools need to make structural changes that will allow students to do both - learn the nature of each of the STEM disciplines and learn that they are interconnected in ways that is more like what they will encounter in real-world problems. This will take concerted efforts at local, state, and national levels if this is to be achieved. (p. 7)

- Policymakers need to consider that our ever-changing world requires updates in the manner that we educate our students of the future. The research around STEM integration as one method of teaching K-12 students is very promising. Current policy initiatives that include high-stakes testing only on mathematics and language arts, school improvement measures based solely on scores on these tests, and teacher performance policies that are based primarily on these tests are hurting our education system. Schools and teachers make educational decisions about what and how to teach based on getting their students to perform better on these tests. This results in students not having access to science, technology, or engineering until later in their education, and in our opinion, the mathematics students are taught represent only the procedural nature of mathematics, not the structure of mathematics. In order to help alleviate this problem, policymakers must fully consider what the research is telling us about how students learn, how they engage, and what can lead to more meaningful citizenry. (p. 7)

STEM integration in K-12 has the potential to help students learn more deeply, enjoy the STEM disciplines, and provide them with better access to future careers (Seymour, Hewitt, \& Friend, 1997). This is a fundamental first step to providing more opportunities for those characteristically underrepresented in STEM fields. Moreover, in the work to continue making this sphere more inclusive and diverse, the need for support systems cannot be understated. Lack of access to and support for aspiring STEM professionals further establishes the need for more integration. Still lagging in the undergraduate space, STEM integration provides students with disciplinary path-related 
opportunities (Seymour et al., 1997). These suggestions, therefore, are to provide access to the underserved. As black women, both in STEM, we posit that the most important implications involve STEM-based (1) access, (2) supports, and (3) role models, allowing black women in STEM every opportunity to be successful. 


\section{REFERENCES}

Anderson, E. (2018). This is what it feels like to be black in white spaces. The Guardian.

Barone, R. (2017). The state of STEM education told through 12 Stats. iDTech. Retrieved from https://www.idtech.com/blog/stem-education-statistics

Bentley, L. C. (2017). Black college students' choice of STEM major: An Analysis of their Perceptions and Experiences in their Intended STEM Pathways (Doctoral dissertation). Vanderbilt University.

Borum, V., \& Walker, E. (2012). What makes the difference? Black women's undergraduate and graduate experiences in mathematics. The Journal of Negro Education, 81(4), 366-378. doi:10.7709/jnegroeducation.81.4.0366

Bronfenbrenner, U. (1977). Toward an experimental ecology of human development. The American Psychologist, 32(7), 513-531. doi:10.1037/0003066X.32.7.513

Carlone, H. B., \& Johnson, A. (2007). Understanding the science experiences of successful women of color: Science identity as an analytic lens. Journal of Research in Science Teaching, 44(8), 1187-1218. doi:10.1002/tea.20237

Castilla, E. J., \& Benard, S. (2010). The paradox of meritocracy in organizations. Administrative Science Quarterly, 55(4), 543-676. doi:10.2189/ asqu.2010.55.4.543

Chubin, D. E. (2007). Voices of the future: African-American Ph.D. candidates in the sciences. In R. J. Burke \& M. C. Mattis (Eds.), Women and minorities in science, technology, engineering and mathematics: Upping the numbers (pp. 91-100). Northampton, MA: Edward Elgar Publishing. doi: $10.4337 / 9781847206879.00013$

Cole, D., \& Espinoza, A. (2008). Examining the academic success of Latino students in science, technology, engineering, and mathematics (STEM) majors. Journal of College Student Development, 49(4), 285-300. doi:10.1353/ csd.0.0018 
Collins, P., McLaughlin, A., Higginbotham, E., Henderson, D., Tickamyer, A., MacDonald, V. M., \& Dance, L. J. (2009). Emerging intersections: Race, class, and gender in theory, policy, and practice. Brunswick, NJ: Rutgers University Press.

Crenshaw, K. (1990). Mapping the margins: Intersectionality, identity politics, and violence against women of color. Stanford Law Review, 43(6), 1241. doi: $10.2307 / 1229039$

Espinosa, L. (2011). Pipelines and pathways: Women of color in undergraduate STEM majors and the college experiences that contribute to persistence. Harvard Educational Review, 81(2), 209-241. doi:10.17763/ haer.81.2.92315ww157656k3u

Falcioni, J. G. (2012). Girls love STEM. Mechanical Engineering-CIME, 134(4), 6-7.

Flaherty, C. (2018). A strengths-based study of black women in STEM. Inside HigherEd. Retrieved from https://www.insidehighered.com/ quicktakes/2018/12/17/strengths-based-study-black-women-stem

Fries-Britt, S., \& Holmes, K. M. (2012). Prepared and progressing: Black women in physics. In C. R. Chambers \& R. V. Sharpe (Eds.), Black female undergraduates on campus: Successes and challenges (Vol. 12, pp. 199-218). Emerald Group Publishing.

Gasman, M., Perna, L. W., Yoon, S., Drezner, N. D., Lundy-Wagner, V., Bose, E., \& Gary, S. (2009). The path to graduate school in science and engineering for underrepresented students of color. In L. Santiague (Ed.), Standing on the outside looking (pp. 63-81). Sterling, VA: Stylus Publishing.

Hill, C., Corbett, C., \& St Rose, A. (2010). Why so few? Women in science, technology, engineering, and mathematics. Washington, DC: American Association of University Women.

Hurtado, S., Eagan, M. K., Tran, M. C., Newman, C. B., Chang, M. J., \& Velasco, P. (2011). "We do science here": Underrepresented students' interactions with faculty in different college contexts. The Journal of Social Issues, 67(3), 553-579. doi:10.1111/j.1540-4560.2011.01714.x PMID:23503924 
Johnson, D. R. (2011). Women of color in science, technology, engineering, and mathematics (STEM). New Directions for Institutional Research, 2011(152), 75-85. doi:10.1002/ir.410

Kanter, R. M. (1977). Men and women of the corporation. New York, NY: Basic Books.

McCall, L. (2008). The complexity of intersectionality. In Intersectionality and Beyond (pp. 65-92). Routledge-Cavendish.

McGee, E. O. (2014). When it comes to the mathematics experiences of Black preservice teachers ... race matters. Teachers College Record, 116(6), 1-50. Available at http://uex.sagepub.com/content/early/recent PMID:26120219

McGee, E. O. (2015). Robust and fragile mathematics identities: A framework for exploring racialized experiences and high achievement among Black college students. Journal for Research in Mathematics Education, 46(5), 599-625. doi:10.5951/jresematheduc.46.5.0599

McGee, E. O., \& Bentley, L. (2017). The troubled success of Black women in STEM. Cognition and Instruction, 35(4), 265-289. doi:10.1080/073700 08.2017.1355211

Moore, T. J., \& Smith, K. A. (2014). Advancing the State of the Art of STEM Integration. Journal of STEM Education: Innovations and Research, 15(1), $5-10$.

Museus, S. D., Palmer, R. T., Davis, R. J., \& Maramba, D. (2011). Racial and ethnic minority student success in STEM education: ASHE higher education report. New York, NY: John Wiley \& Sons.

National Science Foundation, National Center for Science and Engineering Statistics. (2015). Science and engineering degrees, by racelethnicity of recipients: 2002-12. Arlington, VA: Author.

Nix, S., \& Perez-Felkner, L. (2019). Difficulty Orientations, Gender, and Race/Ethnicity: An Intersectional Analysis of Pathways to STEM Degrees. Social Sciences, 8(2), 43. doi:10.3390ocsci8020043

Ong, M., Wright, C., Espinosa, L., \& Orfield, G. (2011). Inside the double bind: A synthesis of empirical research on undergraduate and graduate women of color in science, technology, engineering, and mathematics. Harvard Educational Review, 81(2), 172-209. doi:10.17763/haer.81.2.t022245n7x4752v2 
Perna, L., Lundy-Wagner, V., Drezner, N. D., Gasman, M., Yoon, S., Bose, E., \& Gary, S. (2009). The contribution of HBCUs to the preparation of African American women for STEM careers: A case study. Research in Higher Education, 50(1), 1-23. doi:10.100711162-008-9110-y

Perry, B. L., Link, T., Boelter, C., \& Leukefeld, C. (2012). Blinded to science: Gender differences in the effects of race, ethnicity, and socioeconomic status on academic and science attitudes among sixth graders. Gender and Education, 24(7), 725-743. doi:10.1080/09540253.2012.685702

Rice, D. (2016). The STEM pipeline: Recruiting and retaining African American female engineers. Journal of Research Initiatives, 2(1), 5.

Riegle-Crumb, C., \& Grodsky, E. (2010). Racial-ethnic differences at the intersection of math course-taking and achievement. Sociology of Education, 83(3), 248-270. doi:10.1177/0038040710375689

Robinson, W. H., McGee, E. O., Bentley, L. C., Houston, S. L., \& Botchway, P. K. (2016). Addressing negative racial and gendered experiences that discourage academic careers in engineering. Computing in Science \& Engineering, 18(2), 29-39. doi:10.1109/MCSE.2016.38

Rosa, E. M., \& Tudge, J. (2013). Urie Bronfenbrenner's theory of human development: Its evolution from ecology to bioecology. Journal of Family Theory \& Review, 5(4), 243-258. doi:10.1111/jftr.12022

Seymour, E., Hewitt, N. M., \& Friend, C. M. (1997). Talking about leaving: Why undergraduates leave the sciences. Nature, 386(6625), 566-566.

Stanley, T. L. (2017). Microsoft urges girls to stay in STEM, and change the world, in third year of \#MakeWhatsNext. AdWeek. Retrieved from https:// www.adweek.com/brand-marketing/microsoft-urges-girls-to-stay-in-stemand-change-the-world-in-third-year-of-makewhatsnext/

Watt, S. K. (2003). Come to the river: Using spirituality to cope, resist, and develop identity. New Directions for Student Services, 104(104), 29-40. doi:10.1002s.105 
Weber, K. (2011). Role models and informal STEM-related activities positively impact female interest in STEM. Technology and Engineering Teacher, 71(3), 18.

Willingham, W. W., \& Cole, N. S. (2013). Gender and fair assessment. New York, NY: Routledge Press. doi:10.4324/9781315045115

Yates, N. (2017). Ignored potential: A collaborative road map for increasing African American women in engineering. National Society of Black Engineers. NSBE. 